\title{
EDITORIAL
}

\section{"SCIENTIA, QUAE EST REMOTA AB IUSTITIA, CALLIDITAS POTIUS QUAM SAPIENTIA EST”. UNA MIRADA A LA CNA}

Hemos llegado al tercer número del volumen 40. Por tanto, con esta emisión completamos nuestros 40 años de efectiva e ininterrumpida existencia. En este marco festivo que ha acompañado todas las publicaciones de este año me complace inmensamente anunciar a dos nuevos integrantes del Comité Editorial, quienes sin duda contribuyen a dar aún mayor realce a este selecto órgano, a la vez que a poner más de relieve la importancia de este año de cuadragésimo aniversario. El primero de ellos es el Prof. Dr. D. Gonzalo Rojas Sánchez. Si bien su figura supera ampliamente los confines de las aulas, para invitarle tuvimos en cuenta especialmente su trayectoria en nuestra Facultad, la cual, además de ser en muchos aspectos irrepetible, no puede sino calificarse de trascendental y modélica en el quehacer docente e investigador. El segundo es el Prof. Dr. D. Étienne Picard, iuspublicista y comparatista de gran influencia y fama mundial, tanto desde su actual cátedra en la Universidad de Paris I, Panthéon Sorbonne, como desde su condición de Redactor en Jefe de la Revue Internationale de Droit Comparé, al igual que desde su anterior posición como Director adjunto del Centro de Derecho Europeo y Comparado de la Universidad de Oxford, entre otros tantos puestos de relevancia. Reciban ambos nuestro más caluroso y sentido agradecimiento por el generoso gesto de haber aceptado ser incorporados a nuestro Comité Editorial.

Por otro lado, a la fecha de este número han tenido lugar varios asuntos de interés para el mundo jurídico y para el universitario. Entre las buenas noticias está la entrada en vigencia, este mes, de la modificación a las normas del Código de Comercio sobre el contrato de seguro, en virtud de la Ley 20.667: una modernización digna de las mayores loas; pues sitúa bien la cuestión en el ambiente empresarial de las aseguradoras, al turno que hace cristalizar mecanismos adecuados para el caso de que el asegurado sea una parte débil. Entre las noticias no tan buenas se encuentra el sustancial congelamiento de los presupuestos de CONICYT para el año 2014 (apenas un 3.3\% de incremento en la Ley de Presupuesto promulgada), lo cual sin duda irroga un inmenso perjuicio a los distintos actores e instituciones de la ciencia y la tecnología nacionales. Aparte de lo anterior, resultan francamente preocupantes los rumbos que ha tomado la Comisión Nacional de Acreditación (CNA) en el delicado quehacer que le ha sido confiado. Quisiera detenerme en este punto para ilustrarlo algo más en las siguientes líneas.

Seguramente los lectores nacionales recordarán que la CNA negó la acreditación institucional a la Universidad Bernardo O’Higgins, lo cual constituyó una decisión de primer grado que esta última logró revertir gracias a su apelación ante el Consejo Nacional de Educación (CNED). Así, el CNED, el día 10 de julio de 2013, por el Acuerdo No 039 que a su vez también fue adoptado por unanimidad, dejó sin efecto la primera resolución de la CNA y le confirió a dicha universidad la acreditación institucional solicitada. Sin entrar 
en las vicisitudes de todo el proceso de acreditación, en lo que hace a su decurso formal en sus rasgos más generales todo se había encauzado con normalidad: había una decisión de primera instancia revocada por otra de segunda. Sin embargo, una vez concluido el proceso con la resolución de apelación del CNED, la CNA se permitió hacer una lamentable declaración pública, el día 19 de julio de 2013. En ella "la Comisión Nacional de Acreditación expone las razones por las cuales decidió no acreditar (tanto en primera instancia como al resolver su reposición) a la Universidad Bernardo O'Higgins"; procediendo, para respaldar su decisión negativa, a difundir una reelaboración de sus argumentos críticos presentada de forma sintética y acotada a los ámbitos de evaluación que le parecían más débiles. Por sobre todo, llama la atención la imprudencia -por lo menos-, de que el órgano inferior en un proceso administrativo siga agitando e insistiendo majaderamente en un asunto ya resuelto de manera firme, con una opinión diametralmente contraria, por su superior. La CNA no pareciera haber comprendido que su decisión solo era un eslabón más en la cadena que constituye el proceso de acreditación, el cual debía publicitarse únicamente de acuerdo a lo previsto en la ley respecto a los procedimientos administrativos; por cuanto, además de tratarse de un proceso que debe ventilarse exclusivamente en la forma establecida en la ley dado su carácter público, el particular solicitante de un determinado pronunciamiento estatal tiene el derecho a tener una sola y única resolución definitiva (en este caso, la de segunda instancia), que determine sus derechos con total claridad y sin contrastes, por razones elementales de debido proceso, derechos adquiridos y certeza jurídica. Casi al terminar la señalada declaración pública, la CNA dice: "Con todo, la Comisión Nacional de Acreditación reitera su reconocimiento de las disposiciones legales vigentes, que facultan a la UBO para apelar de esta decisión y que determinaron finalmente que su recurso fuera acogido por el CNED, otorgándosele dos años de acreditación". Por cierto, la contraposición que necesariamente contiene la locución adverbial "con todo", implica una reafirmación de lo dicho anteriormente aunque pudiera aparecer prima facie contradictorio con la oración siguiente: "eres una mala persona, con todo, eres mi amigo"; "esta universidad no merece acreditarse, con todo, el superior la acreditó". Así es que este reconocimiento (formal) de la CNA respecto de la legalidad de la acreditación finalmente lograda por dicha universidad, con todo, deja en pie la contradicción del inferior hacia el superior; siendo dudoso, entonces, al menos sustancialmente, el respeto a la jerarquía, a la unidad y legalidad del procedimiento y a los propios derechos adquiridos de la solicitante.

Antes de dejar de lado estos acontecimientos, debo poner de relieve que en el mismo proceso salió a la luz el "Informe Final Comisión Nacional de Acreditación" No 87/2012, de 19 de noviembre de 2012, emitido por la Contraloría General de la República, a través de la División de Auditoría Administrativa, Área de Educación, Trabajo y Previsión Social. Este documento establece cuestiones de interés para contextualizar el asunto que quiero tratar a continuación. Pues la materia del Informe es "Sobre el cumplimiento de la normativa $y$ transacciones de la Comisión Nacional de Acreditación. CNA" (el período en examen correspondiente a esta auditoría del Plan Anual de Fiscalización 2012, corrió desde el 2 de enero al 31 de diciembre de 2011). En la ocasión se decidió fiscalizar exclusivamente los aspectos relativos a las acreditaciones institucionales. Y, entre las múltiples anomalías detectadas, una de gran entidad fue la falta absoluta de elaboración y promulgación de los reglamentos 
que legalmente la CNA debe emitir para conducir tales procesos administrativos; asunto de una gravedad que no hace falta referir entre juristas. En efecto, el Informe de Contraloría en comento señala en su p. 10: "La Comisión no ha elaborado un reglamento sobre la forma, condiciones y requisitos especificos, para el desarrollo de los procesos de acreditación institucional, infringiendo con ello, lo establecido en los artículos 15 y 16 de la precitada ley $N^{\circ} 20.129$ y el principio de certeza jurídica que debe imperar en la materia".

Pues bien, si miramos nosotros los procesos de acreditación de postgrado -y es a esto a lo que quiero aludir fundamentalmente en este editorial-, encontramos el mismo vicio de falta del necesario reglamento al menos para fijar las pautas o criterios de evaluación; circunstancia agravada por el hecho de que aquel informe de la Contraloría debió haber servido como advertencia frente a esta grave carencia. En efecto, hasta la fecha sí ha habido reglamentos sobre la conducción del procedimiento en sus aspectos más generales -ninguno de gran calidad, y tal vez por lo mismo, en una cantidad sucesiva enorme y bastante desorientadora-. Pero en lo que hace a las pautas, criterios o estándares, generales o específicos, que sirvan para medir los programas de postgrado -es decir, al núcleo mismo de una acreditación-, todavía no existe el reglamento que ordena la Ley 20.129, en el inciso final del artículo 44 y en el artículo 45:

"Art. 44. ... Un reglamento de la Comisión establecerá la forma, condiciones y requisitos para el desarrollo de los procesos de acreditación de programas de postgrado".

Art. 45. Corresponderá a la Comisión fijar y revisar periódicamente los criterios de evaluación para la acreditación de programas de postgrado, a propuesta de un comité consultivo de acreditación de postgrado".

Los criterios, pautas o estándares, generales o específicos, para la evaluación de un programa de postgrado quedan comprendidos en la forma, requisitos y condiciones para el desarrollo de los procesos de acreditación. De manera que dichos criterios deben establecerse por medio de un reglamento de la CNA (inciso final del artículo 44 de la Ley 20.129), el cual debe emitirse por la propia Comisión a propuesta del Comité Consultivo de Acreditación de Postgrado (artículo 45 de la Ley 20.129). Por su parte, de momento, en ausencia de tal reglamento, debe ser atendido el artículo $4^{\circ}$, transitorio, de la Ley 20.129:

"Mientras la Comisión Nacional de Acreditación no defina las pautas de evaluación de programas de postgrado a que se refiere el artículo 44, ellos corresponderán a aquellos definidos por la Comisión de Evaluación de Calidad de Programas de Postgrado".

Por tanto, la cuestión queda regulada por el Decreto Supremo No 3380, del año 2000, que estaba referido al órgano antecesor, el cual "establece normas que fijan bases, criterios y procedimientos para la evaluación experimental de la calidad de los programas de postgrado de las universidades autónomas". En efecto, en este lugar, al hilo del artículo 5º se fijan las "bases y criterios generales a considerar para la evaluación acreditativa de un programa de doctorado". Y en relación con lo anterior, el artículo $3^{\circ}$, letra c), del mismo Decreto Supremo, indica: 
"Los Comités deberán, conforme a una pauta y a los criterios indicados en estas normas, evaluar los Programas de Postgrado que se presenten a su consideración, pudiendo solicitar la participación de evaluadores externos".

Así entonces, las normas que originalmente rigieron a la CONAP establecen que la CNA (a través de sus Comités de Área) debe aplicar las “pautas y criterios” que se encuentren entre esas mismas normas, y no otras -como desde luego ya se podría señalar solo con el respaldo de los artículos 6 y 7 de la Constitución, y 2 de la Ley 18.575-. Ahora bien, debo subrayar de la manera más categórica que en el artículo $5^{\circ}$ del Decreto Supremo No 3380, tal como lo dice el título, solo se establecen "criterios generales", no específicos. Para demostrarlo, podemos fijarnos en las consideraciones simplemente generales que se hace en dicho artículo, al interior del ítem "Profesores del Programa", respecto a los criterios de evaluación de estos en los programas de postgrado:

"El Programa deberá estar a cargo de un núcleo estable de académicos con jornada completa en la Institución proponente. Los docentes deben constituir grupos académicos que aporten un medio estimulante y variado que complemente la formación del candidato. La Universidad deberá definir el cuerpo de directores de tesis, los profesores encargados de los cursos y los profesores visitantes. La cantidad requerida de profesores en cada categoría variará de acuerdo a los objetivos y amplitud del programa. En todo caso, la Institución proponente deberá contar con un número de profesores que pertenezcan a las dos más altas jerarquías académicas, con jornada completa que asegure la diversidad, estabilidad del programa y adecuada atención de los estudiantes".

La conclusión es obvia: no hay criterios específicos para evaluar a los profesores de los programas de postgrado, sino solo un conjunto de criterios generales para medirlos; y ello, siempre como grupo, no individualmente. Ya sorprende que a pesar de este insalvable vacío la CNA se atreva a resolver los respectivos procesos de acreditación, pues no atino a encontrar el sustento legal y constitucional para ello. Pero sorprende más un nuevo dato que ahora aporto. En la página web de CNA, se encuentra desde hace poco un documento incorporado en la sección "Cómo acreditarse", dentro de "Normas y procedimientos", "Acreditación de programas de postgrado", que lleva por título "Estándares de Productividad por comités de área". Solo reportaré lo establecido por el Comité de Área de Ciencias Jurídicas:

\section{"Doctorado}

2 Artículos indexados o con referato, al año pudiendo reemplazarse por cuatro publicaciones no indexadas o capitulos de libros al año; o 1 libro con comité editorial cada 3 años; o 1 libro sin comité editorial al año.

1 proyecto concursable (FONDECYT o equivalente externo a la Institución que imparte el Programa) cada 5 años como investigador principal o co-investigador.

1 http://www.cnachile.cl/wp-content/uploads/2010/05/CRITERIOS-COMITÉS-DE-AREA.pdf 
Magíster Académico

1 Artículo indexado o con referato, al año pudiendo reemplazarse por 3 artículos no indexadas o capítulos de libros al año; o 1 libro con comité editorial cada 5 años; o 1 libro sin comité editorial cada 2 años.

1 proyecto concursable (interno o externo a la Institución que imparte el Programa) cada 5 años como investigador principal o co-investigador.

Magíster Profesional

1 Publicación ISI, Scielo, Scopus, Latindex catálogo, capítulos de libro con comité editorial, libros con comité editorial y/o artículos de revistas con comité editorial, por académico al año.

A lo menos un proyecto adjudicado y/o asistencia técnica realizada en los últimos 5 años (en calidad de responsable o co-investigador).

No me referiré al aspecto sustantivo de estos estándares, que no presentan gran precisión ni proporcionalidad interna ni, finalmente, tampoco parecen una medida prudente para medir el nivel básico de producción de todo profesor en estos tres ámbitos (de hecho, no tengo conocimiento de que este cálculo se base en algún estudio objetivo de la realidad jurídica nacional que le sirva de fundamento). Pero sí llamaré la atención respecto de que, según dice el documento mismo, se quiso consultar a los Comités de Área por cuanto el propio artículo 44 de la Ley 20.129 indica que la acreditación de postgrado se realiza según: “... los criterios o estándares establecidos para este fin por la comunidad científica o disciplinaria correspondiente". Deben aclararse tres órdenes de cosas. La primera es que resulta sorprendente que el Comité de Área de Ciencia Jurídica no parezca haber tenido en cuenta las normas de la Ley 20.129 -artículos 44, 45 y $4^{\circ}$ transitorio-, y del Decreto Supremo No 3380 -especialmente los artículos $3^{\circ}$ c) y 5º-; las cuales les resultan, sin embargo, vinculantes. La segunda es que el Comité de Área de Ciencia Jurídica es un órgano autoconvocado por la propia CNA, sin asesoría o consulta alguna a los miembros de la comunidad científica o displinaria correspondiente. Por ejemplo, ningún Jefe de Programa de Postgrado en Derecho, o esta Revista, en cuanto es uno los medios de difusión más importantes de la producción de los profesores nacionales, jamás ha sido consultado a este respecto. Por lo tanto, aparece como una petición de principios atribuir a ese grupo el carácter de representativo de la "comunidad correspondiente", como pretende explícitamente la CNA, y dar así la ley por satisfactoriamente cumplida. En tercer lugar, los criterios o estándares respecto de la productividad de los profesores, tal como hemos visto en el propio artículo 44 y en el 45, deben establecerse por medio de un reglamento, lo que no ocurre en este caso, el cual tiene que ser sancionado por la CNA a propuesta del Comité Consultivo, lo cual tampoco ocurre por cuanto aquí se asumió la propuesta del Comité de Área, que es un órgano diferente. Por tanto, estos estándares propuestos por la CNA no tienen validez legal alguna.

Yo lamento esta situación en la que se encuentran los comisionados. Verdaderamente tengo la impresión de que ellos hacen un leal y significativo esfuerzo por cumplir correctamente su cometido. Pero, objetivamente, se les escapan estos aspectos jurídicos que, si bien son ajenos a sus áreas de especialidad, resultan igualmente insoslayables para la justicia de los procesos de acreditación. Así, sin una asesoría adecuada en las materias que he tratado, 
terminan derrochando su esfuerzo bajo un cierto ambiente de desorden interno que les hace incurrir en vicios, como la falta de los debidos reglamentos, respecto del cual la Contraloría General de la República ya los había prevenido. De hecho, en el ya referido Informe No 87, p. 3, se dice expresamente: "Carencia de procedimientos de control. / La revisión practicada, permitió comprobar que dicha Institución no cuenta con manuales de procedimientos internos, relativos a las áreas de acreditación institucional, de pregrado y postgrado, situación que no se ajusta al principio de transparencia institucional e incrementa la exposición al riesgo, lo cual afecta su estructura de control interno, además de sus objetivos".

Considerando las altas personalidades que forman parte de la Comisión Nacional de Acreditación, sé que ellos sabrán reflexionar sobre estos asuntos a la hora de tomar noticia de su significación jurídica. Y, desde luego, todos los miembros de esta Revista, actores entusiastas de la comunidad científica jurídica, nos ponemos a su disposición. Confío en que los comisionados tendrán en cuenta la sentencia que Cicerón, De Officiis 1.19.63, pone en boca de Platón: "Scientia, quae est remota ab iustitia, calliditas potius quam sapientia est" ("La ciencia que está lejana a la justicia, es ardid más que sabiduría”).

Prof. Dr. Patricio-Ignacio Carvajal Pontificia Universidad Católica de Chile 